\title{
Assessment of the "Oli-Picker" harvester in
}

\section{northeast Portugal}

Arlindo Almeida ${ }^{1}$; José Peça ${ }^{2}$

(1) Centro de Investigação de Montanha - Escola Superior Agrária de Bragança -Portugal - acfa@ipb.pt (2) Departamento de Engenharia Rural da Universidade de Évora - Portugal

\section{Introduction}

The Oli-picker harvester operates brushing the tree canopy with a spiked cylindrical coomb (Figs.1 and 2).

Previous field observations, over a period of two campaigns (Almeida 2007) revealed work rates of 10 to 25 trees per hour depending on the work methodology and canopy volume, which is a modest result compared to the 50 to $\mathbf{8 0}$ trees per hour of trunk shaker based harvesting systems (Almeida, 1999 and Peça, 2002).

The great advantage of the Oli-picker relative to trunk shakers can be found in the harvesting of large trees common in old traditional orchards of the Northeast of Portugal, Spain and Italy. In such large trees trunk shakers are not efficient .

This paper presents results from three years of observation of the Oli-picker harvester in Trás-osMontes (northeast of Portugal), including the methodologies of work followed in the field, the work rates found and expected costs.

\section{Material and methods}

The Oli-picker was observed in traditional olive orchards of Trás-os-Montes, without irrigation, and mainly with large trees of three main cultivars: Verdeal Transmontana, Cobrançosa and Madural.

Work rates were measured in two different methods of work organization.

Work method 1 - The Oli-picker is positioned in the field (station) to make possible to reach one, two or in a few occasions four trees trees (Figs. 3 and 4). Different stations were required to complete the harvest of a single tree. Four labourers shake the canopy with long wood poles, to complete the harvest of each tree.

Work method 2 - For a particular tree or pair of trees, the Oli-picker is positioned in a single station. It will only be moved after the tree had been totally harvested. To assist in the detachment of fruits out of reach three labourers shake the canopy with long wood poles while a fourth labourer operates a mechanical branch shaker (Fig. 7).

The Oli-picker and other equipment and labour annual costs of were estimated.

$$
\mathrm{C}=\left(\frac{\mathrm{CT} 1+\mathrm{CT} 2+\mathrm{TC}}{\mathrm{WR}}+\frac{\mathrm{OC}+\mathrm{CC}+\mathrm{SC}}{\mathrm{TNT}}+\frac{8 \times \mathrm{LC}}{\mathrm{WR} \times \mathrm{HWD}}\right) \times \frac{1}{\mathrm{OPT}}
$$

C - cost/kg of olives harvested; SC - Mechanical branch shaker cost/year; CT1 - Cost/hour of Tractor 1; LC - Labour cost/day; CT2 - Cost/hour of Tractor 2; WR - Oli-picker work rate; TC - Oli-picker cost/year; HWD

\section{DISCUSSION AND CONCLUSIONS}

The Oli-picker in conjunction with hand shakers may be regarded as a useful tool for olive harvesting of trees with large canopies, bearing in mind that values close to $100 \%$ of detachment can be reached and that for such trees trunk shakers are inadequate. However, to make operational costs competitive it is important to improve work organization and above all to increase olive production on these traditional olive orchards. In the former aspect, the increase in the number of hand held shakers concentrated in lower branches should be envisaged in the near future, and a proposal for a R\&ED project put forward accordingly.

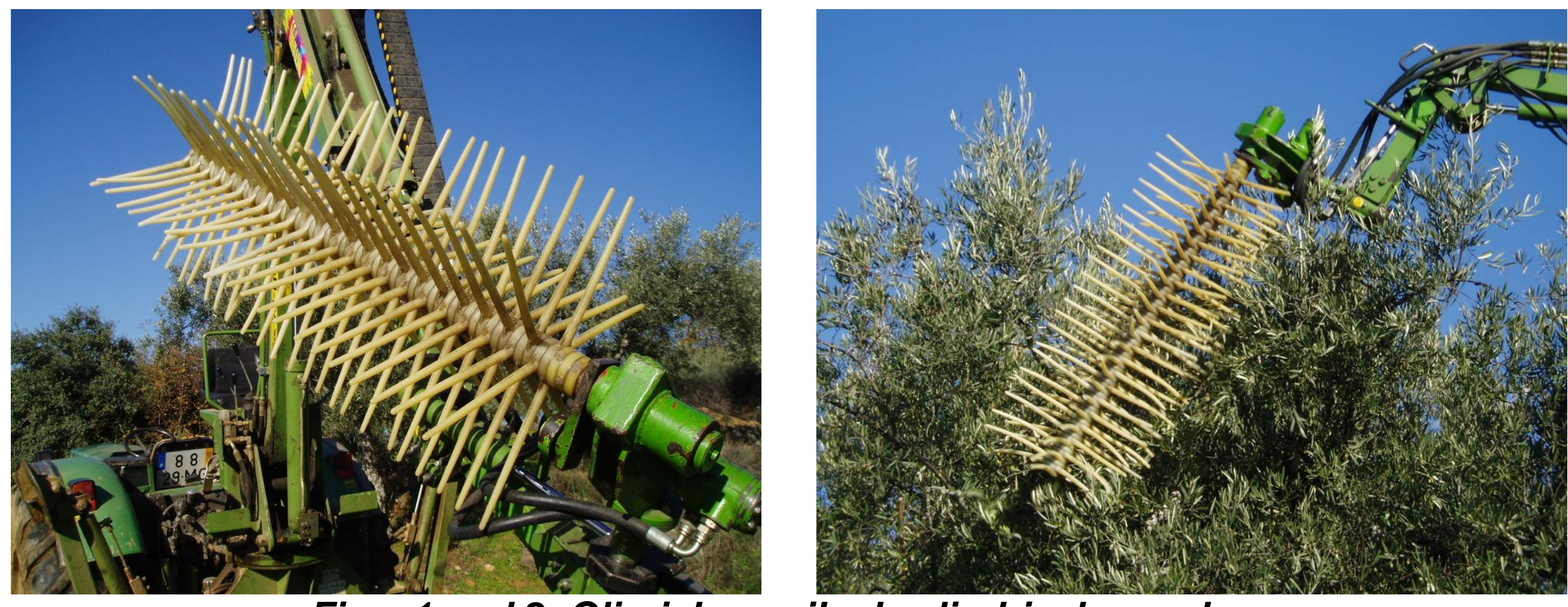

Figs. 1 and 2- Oli-picker spiked cylindrical coomb
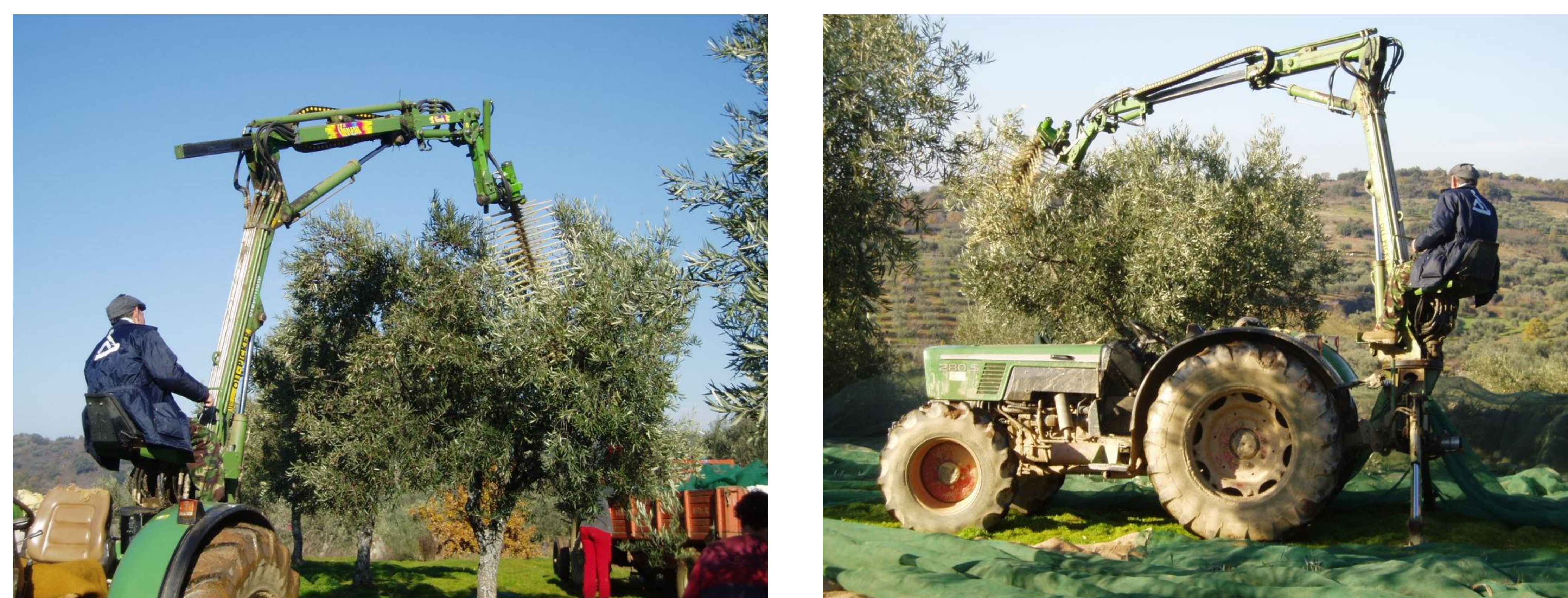

Figs. 3 and 4 - Oli-Picker harvester at work in a station.

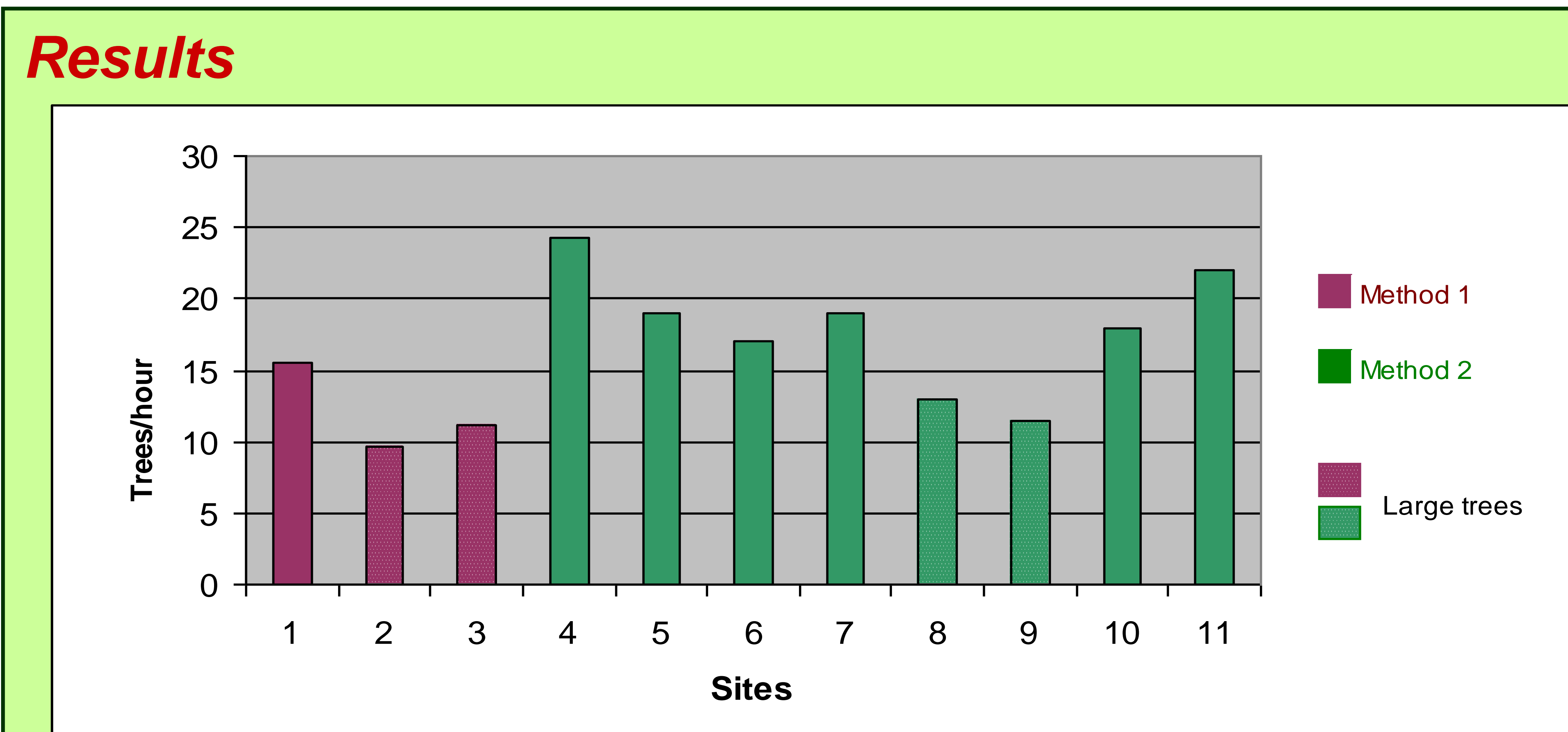

Fig. 5- Oli-picker work rates

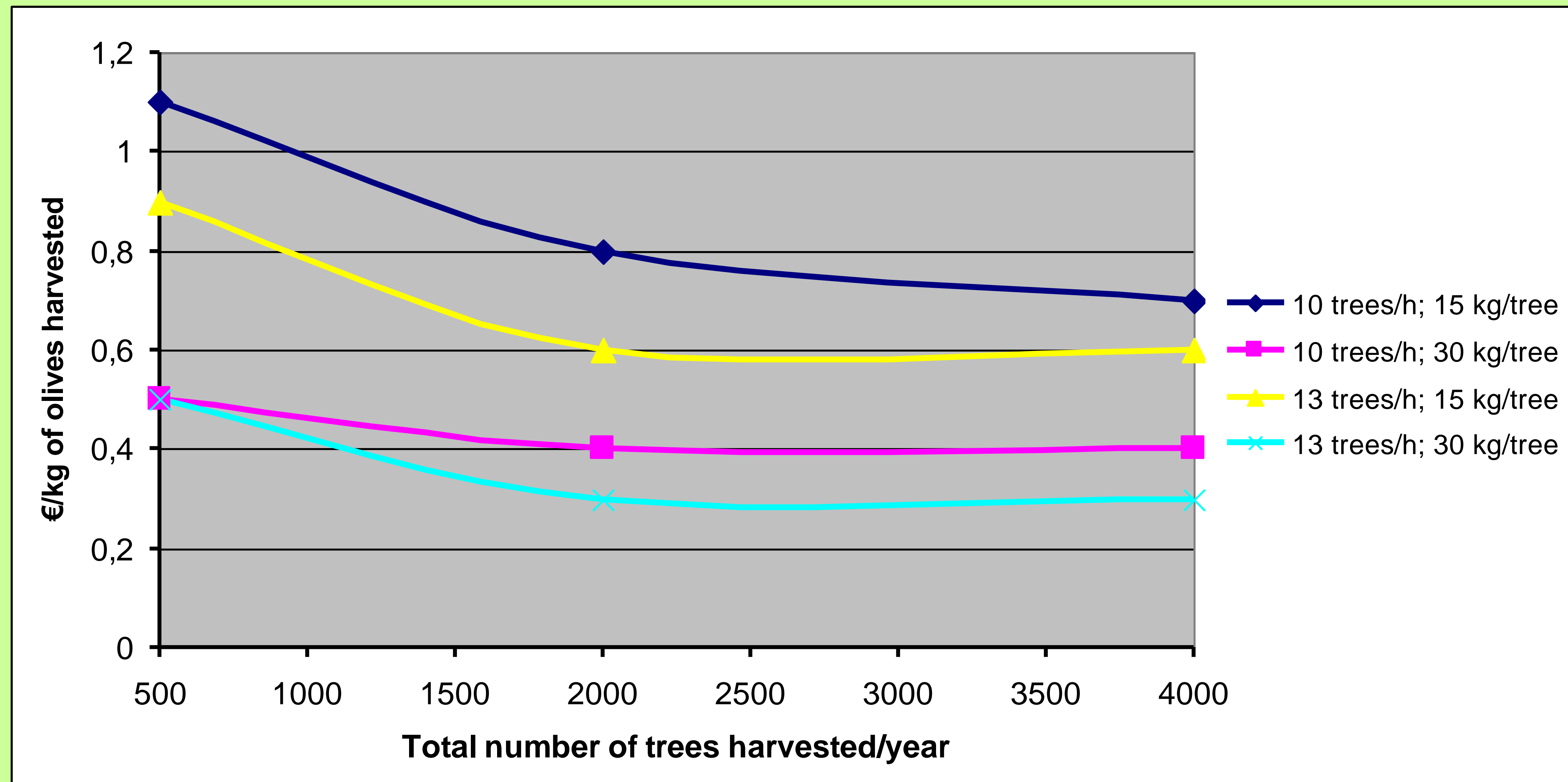

Fig. 6- Cost/kg of olives harvested according to Oli-picker work rate and olives produced per tree

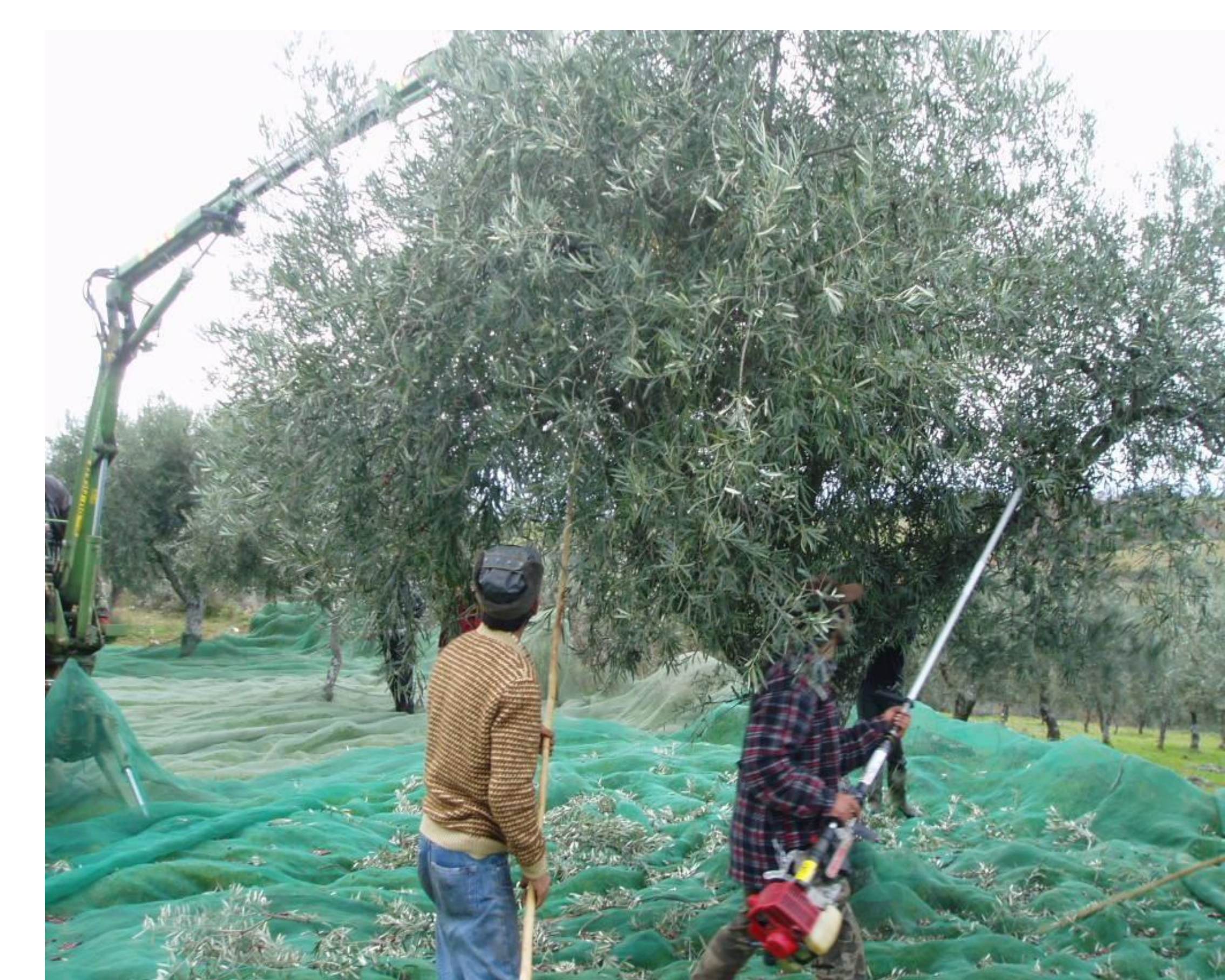

Fig. 7- Oli-Picker and a mechanical branch shaker operating simultaneously.

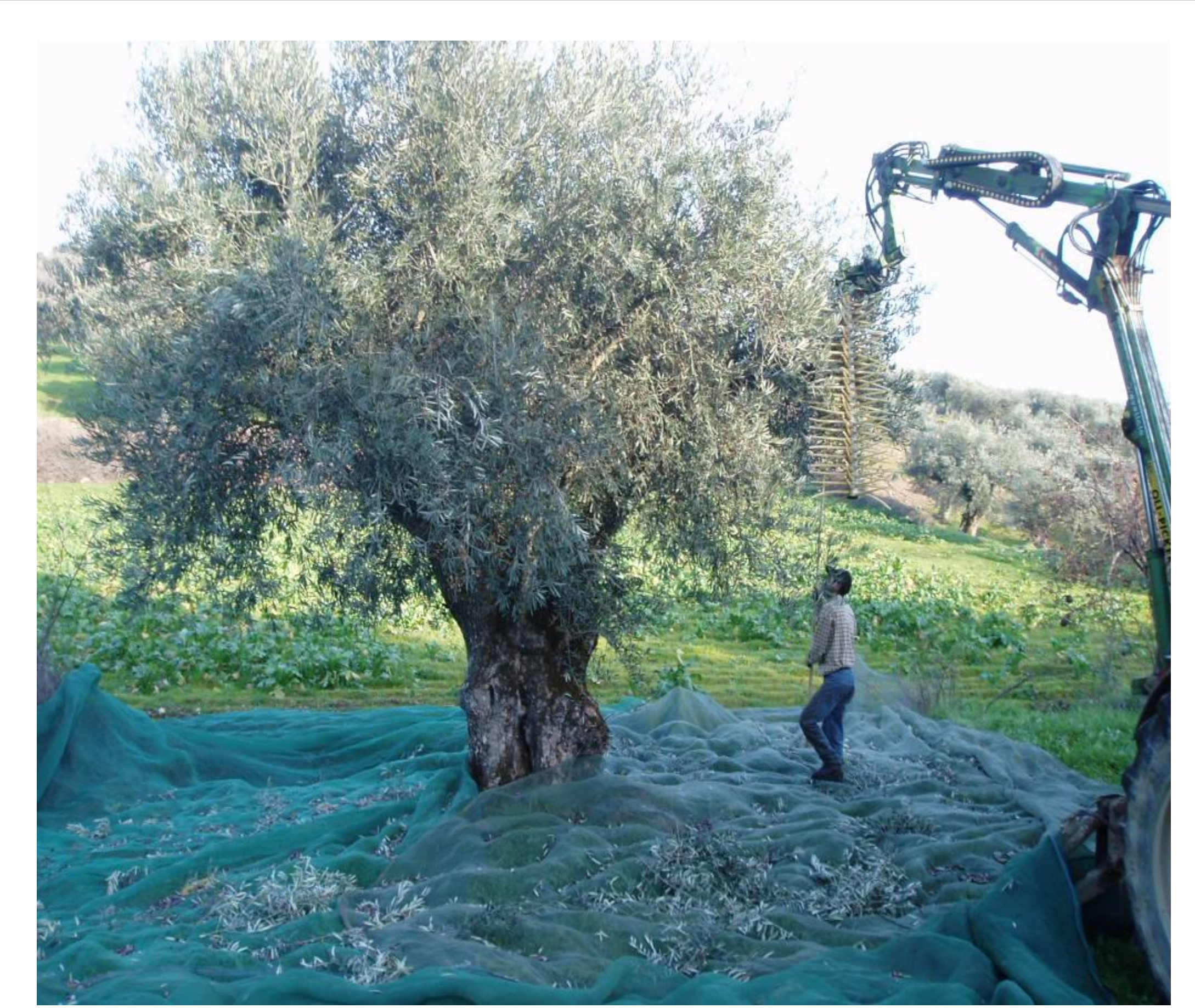

Fig. 8- In a large tree the detachment is more eficiently than with a trunk shaker. 